\title{
How common are depression and anxiety in adolescents with chronic fatigue syndrome (CFS) and how should we screen for these mental health co-morbidities? A clinical cohort study
}

\author{
Maria E. Loades ${ }^{1,2}$ (D) $\cdot$ Rebecca Read $^{1} \cdot$ Lucie Smith $^{1} \cdot$ Nina T. Higson-Sweeney ${ }^{1} \cdot$ Amanda Laffan $^{3} \cdot$ Paul Stallard $^{4}$. \\ David Kessler ${ }^{2}$ Esther Crawley ${ }^{2,3}$
}

Received: 13 November 2019 / Accepted: 12 September 2020 / Published online: 22 September 2020

(c) The Author(s) 2020

\begin{abstract}
Adolescents with Chronic Fatigue Syndrome/Myalgic Encephalomyelitis (CFS/ME) appear to be more likely to experience anxiety and/or depression using Patient Reported Outcome Measures (PROMs). However, we do not know how accurate these are at detecting problems in this patient group given the primary symptom of fatigue. We aimed to accurately determine the prevalence of anxiety/depression using gold-standard diagnostic interviews and evaluate the accuracy of PROMs measuring mood disorders in this patient group. We conducted a cross-sectional epidemiological study in a specialist tertiary paediatric CFS/ME service, England. The participants were164 12-18-year olds with clinician confirmed CFS/ME and their parents. The measures were a semi-structured diagnostic interview, the Kiddie Schedule for Affective Disorders and Schizophrenia, K-SADS, and questionnaires (Revised Children's Anxiety and Depression Scale, RCADS; Spence Children's Anxiety Scale, SCAS; Hospital Anxiety and Depression Scale, HADS). Parents completed the RCADS-P. 35\% met the criteria for at least one common mental health problem. $20 \%$ had major depressive disorder, and $27 \%$ an anxiety disorder, with social anxiety and generalised anxiety being the most common. There was high co-morbidity, with $61 \%$ of those who were depressed also having at least one anxiety disorder. The questionnaires were moderately accurate (AUC $>0.7$ ) at detecting clinically significant anxiety/depression, although only the RCADS-anxiety reached the predefined 0.8 sensitivity, 0.7 specificity target. Mental health problems are particularly common amongst adolescents with CFS/ME. Most screening tools were not sufficiently accurate in detecting clinically significant anxiety and depression, so these should be used with care in combination with thorough psychological/psychiatric assessment.
\end{abstract}

Keywords Prevalence $\cdot$ CFS $\cdot$ Mood $\cdot$ Depression $\cdot$ Anxiety $\cdot$ Screeni

Electronic supplementary material The online version of this article (https://doi.org/10.1007/s00787-020-01646-w) contains supplementary material, which is available to authorized users.

Maria E. Loades

m.e.loades@bath.ac.uk

1 Department of Psychology, University of Bath, Bath BA2 7AY, UK

2 Bristol Medical School, University of Bristol, Bristol, UK

3 Royal United Hospital, Bath, UK

4 Department of Health, University of Bath, Bath, UK

\begin{tabular}{|c|c|}
\hline \multicolumn{2}{|c|}{ Abbreviations } \\
\hline \multirow[t]{2}{*}{ CFS/ME } & Chronic Fatigue Syndrome/Myalgic \\
\hline & Encephalomyelitis \\
\hline \multirow[t]{2}{*}{ DSM-5 } & Diagnostic and Statistical Manual of Mental \\
\hline & Disorders version 5 \\
\hline GAD & Generalised anxiety disorder \\
\hline KSADS & $\begin{array}{l}\text { Kiddie schedule for affective disorders and } \\
\text { schizophrenia }\end{array}$ \\
\hline MDD & Major depressive disorder \\
\hline NHS & National Health Service \\
\hline $\mathrm{OCD}$ & Obsessive-compulsive disorder \\
\hline PTSD & Post-traumatic stress disorder \\
\hline CFQ & Chalder Fatigue Questionnaire \\
\hline HADS-A & Hospital Anxiety and Depression \\
\hline & Scale-Anxiety \\
\hline HADS-D & Hospital Anxiety and Depression \\
\hline & Scale-Depression \\
\hline
\end{tabular}




$\begin{array}{ll}\text { RCADS-A } & \begin{array}{l}\text { Revised Children's Anxiety and Depression } \\ \text { Scale-Any Anxiety } \\ \text { Revised Children's Anxiety and Depression } \\ \text { Scale-Depression } \\ \text { SpADS-D }\end{array} \\ \text { SCAS } & \begin{array}{l}\text { Spence Children's Anxiety Scale } \\ \text { SF36PFS }\end{array} \\ & \begin{array}{l}\text { Short Form 36 Physical Functioning } \\ \text { Subscale }\end{array}\end{array}$

\section{Introduction}

Chronic Fatigue Syndrome (CFS/ME) is common and disabling [1]. Around 30\% of adolescents have high levels of depressive symptoms on standardised questionnaires [2-4]. A similar proportion have heightened anxiety, particularly social and separation anxiety [5]. However, as the symptoms of anxiety (e.g. restlessness) and depression (e.g. fatigue, sleep problems) overlap with those of CFS/ME, symptom conflation may lead to inaccurate estimates when relying on questionnaires. In addition, adolescents with CFS/ME do not feel questionnaires (Patient Reported Outcome Measures, PROMs) accurately capture their symptoms [6]. Some PROMs were designed for adults with no input from adolescents with CFS/ME [7]. It is; therefore, not clear whether the published prevalence rates are accurate or not. This could be resolved with diagnostic interviews. The existing studies using diagnostic interviews have also found high rates of anxiety disorders and depression, but are limited by small sample size and therefore, potential bias [8, 9] and are based on the previous versions of the diagnostic criteria.

The aim of this study was to (1) assess prevalence using diagnostic interviews with the current DSM-5 criteria in a large clinical cohort and (2) assess the accuracy of commonly used PROMs in detecting mental health problems in this population.

\section{Patients and methods}

This was a cross-sectional study in a clinical cohort.

\section{Participants}

Consecutively referred adolescents, age $12-18$, with a clinician confirmed diagnosis of CFS/ME at their initial assessment at a specialist paediatric CFS/ME team within the National Health Service (NHS) in England were invited to participate. Recruitment spanned September 2016 to February 2019. Exclusion criteria were (1) having learning difficulties which precluded the completion of the study measures and (2) being unable to complete the diagnostic interview due to the functional impact of their CFS/ ME or due to insufficient English ability. After 6 months, we adapted recruitment to include participants of the MAGENTA randomised control trial [10] (see Online Supplementary Materials Appendix 1 for further details).

\section{Measures}

Self-reported age, sex, ethnicity and school attendance were collected routinely at clinical assessment.

KSADS - The Kiddie Schedule for Affective Disorders and Schizophrenia [11] is a semi-structured diagnostic interview for children and adolescents age 6-18. It is the gold-standard instrument for diagnosing depression [12, 13]. We focused on present psychiatric disorders (not previous, lifetime disorders). We used the following sections: MDD, panic disorder, agoraphobia, separation anxiety disorder, social anxiety disorder, phobic disorders, generalised anxiety disorder, obsessive-compulsive disorder, posttraumatic stress disorder, eating disorders and substance-related disorders [14]. We did not screen for: psychosis, conduct disorder, attention-deficit hyperactivity disorder, developmental disorders, enuresis and encopresis, nor did we screen for mania or disruptive mood dysregulation disorder which require historical information.

RCADS-The Revised Children's Anxiety and Depression Scale [15] is made up of 47 items, of which 10 ask about depression. Respondents rate each item on a $0-3$ scale and the total score is summed to give a depression score, where a higher score indicates greater depressive symptoms. Raw scores can be converted to age- and gender-adjusted $T$ scores, which have a mean of 50 and a standard deviation of 10 , using standardised tables. The RCADS has strong psychometric properties $[16,17]$ and good convergent validity with the KSADS [18]. Adolescents and parents completed the RCADS and RCADS-P, respectively. A briefer, 25 item versions of the RCADS and RCADS-P were also tested in the current study.

$H A D S$ - The Hospital Anxiety and Depression Scale [19] has 14 items: 7 depressive and 7 anxiety items. The HADS was designed to minimise overlap with physical disorders by excluding somatic symptoms. It has been validated for use with adolescents and has acceptable psychometric properties in this population [20]. Respondents rate items on a 0-3 scale, and the items for each subscale are summed to give a total score, with higher scores indicating more symptoms.

$S C A S$ - The Spence Children's Anxiety Scale [21, 22] is a 45-item self-report scale designed to measure symptoms relating to DSM-IV separation anxiety, social phobia, obsessive-compulsive disorder, panic-agoraphobia, generalised anxiety and fears of physical injury [23]. Each item is scored on a 0 (never)-3 (always) scale. The SCAS contains 7 positive filler questions, not included in the total score. The 38 anxiety items are summed, generating a total score out of a 
possible 114, with a higher score indicating greater anxiety. The SCAS has good psychometric properties [24].

Fatigue-CFQ: The Chalder Fatigue Questionnaire [25] has 11 items and responses are on a 0 (less than usual) -3 (much more than usual) scale. Responses are summed to create a total score. Higher scores indicate more fatigue. It has good reliability and validity in CFS samples [26] and has been used as an outcome measure adolescents with CFS [27, 28].

Disability-SF36-PFS: The 10 item Short Form-36 Physical Functioning Subscale [29] has three response options per item; 0 (yes limited a lot), 5 (yes, limited a little), and 10 (no, not limited at all). Responses are summed, resulting in a total score out of a possible 100. Higher scores indicate better physical functioning. The psychometric properties of this scale are acceptable in adolescents with CFS [30].

\section{Ethical Approval}

Ethical approval was granted by the NHS Health Research Authority (16/SW/036) and the Department of Psychology at the University of Bath (16-203). The MAGENTA trial was approved by the NHS Health Research Authority (15/ SW/0124).

\section{Procedure}

Potential participants were provided with a participant information sheet at their initial clinical assessment and offered the opportunity to agree to be contacted by the research team via telephone or email. Interested participants were provided with further information, and we subsequently obtained verbal consent and written consent, either online via REDCap (research electronic data capture [31]) or pen-and-paper. For participants who were $<16$ years old, parental consent and adolescent assent were obtained.

Those participants recruited within the MAGENTA trial were assessed for eligibility for the trial by their assessing clinician (eligibility criteria are detailed in the study protocol [10]). Eligible patients who consented to be contacted were subsequently given further information about the study by a research nurse over the telephone, who obtained consent/ assent via REDCap. From February 2017, this included consenting to participate in the KSADS interview for those participants of the MAGENTA trial who were $\geq 12$ years old.

Participants provided consent to use data collected from the following clinical PROMs completed prior to first clinical assessment: SCAS, HADS, the CFQ and the SF36PFS. After recruitment, participants completed the RCADS. Participants interviewed as part of the MAGENTA trial did not complete the RCADS.

The KSADS interview was conducted via Skype $(N=48,29.3 \%)$, telephone $(N=89,54.3 \%)$, at the hospital site $(N=13,7.9 \%)$ or the participant's home $(N=10$, $6.1 \%$ ), according to participant preference. The KSADS has been administered by telephone in other studies [32, 33 ]and diagnostic interviews have been administered via videoconferencing and telephone in chronic illness samples to minimise participant burden [34]. Participants were given the option of being interviewed with a parent present. If they opted to be interviewed alone $(N=31$, $18.9 \%$ ), the parent was briefly interviewed separately. The questions asked of parents when interviewed alone were focused on the more observable, behavioural aspects of depression and anxiety, such as irritability, and were also informed by the areas that the adolescent interview had highlighted. Parents were invited to add any other concerns they had. The resultant information was integrated into a summary judgement by the interviewer; due to the internalising nature of depression and anxiety, adolescent report given more weight when there were discrepancies between self- and parent-report. Research assistants were trained to accommodate the needs of young people with CFS/ME; interviews were kept brief, participants could take a rest breaks whenever they wished and the interview could be conducted over several sessions within the same week where needed. Interviews lasted between 9 and 199 min in total (mean 44.43, SD 28.39).

Interviews were conducted by research assistants (psychology students) who had completed a two-day training course on administration. Specific emphasis was on training the interviewers how to ask about each symptom screened for on the KSADS in a manner appropriate to the context of CFS/ME. For example, when asking about anhedonia, questions were asked about what activities adolescents engaged in currently that gave them enjoyment, even if they were unable to do the enjoyable activities they usually would. Similarly, when questions about fatigue particularly emphasised the link between fatigue and other mood relevant symptoms and experiences.

Research assistants were subsequently closely supervised, including of audio recordings of interviews. Following each interview, the interviewer made a provisional diagnostic conclusion, which was reviewed and discussed with an experienced mental health professional (ML) for all cases. ML attended a 2-day training course on KSADS administration at the outset of the study, including taking part in inter-rater reliability exercises. In addition, 23 (14\%) interviews were checked by a second interviewer, blind to the conclusion made by the interviewer. Both raters agreed on 195 of 207 (94.2\%) diagnostic decisions, which is considered fair agreement (Cohen 1960), $\kappa=0.20 p=0.007,95 \%$ CI $[-0.16,0.56]$. 


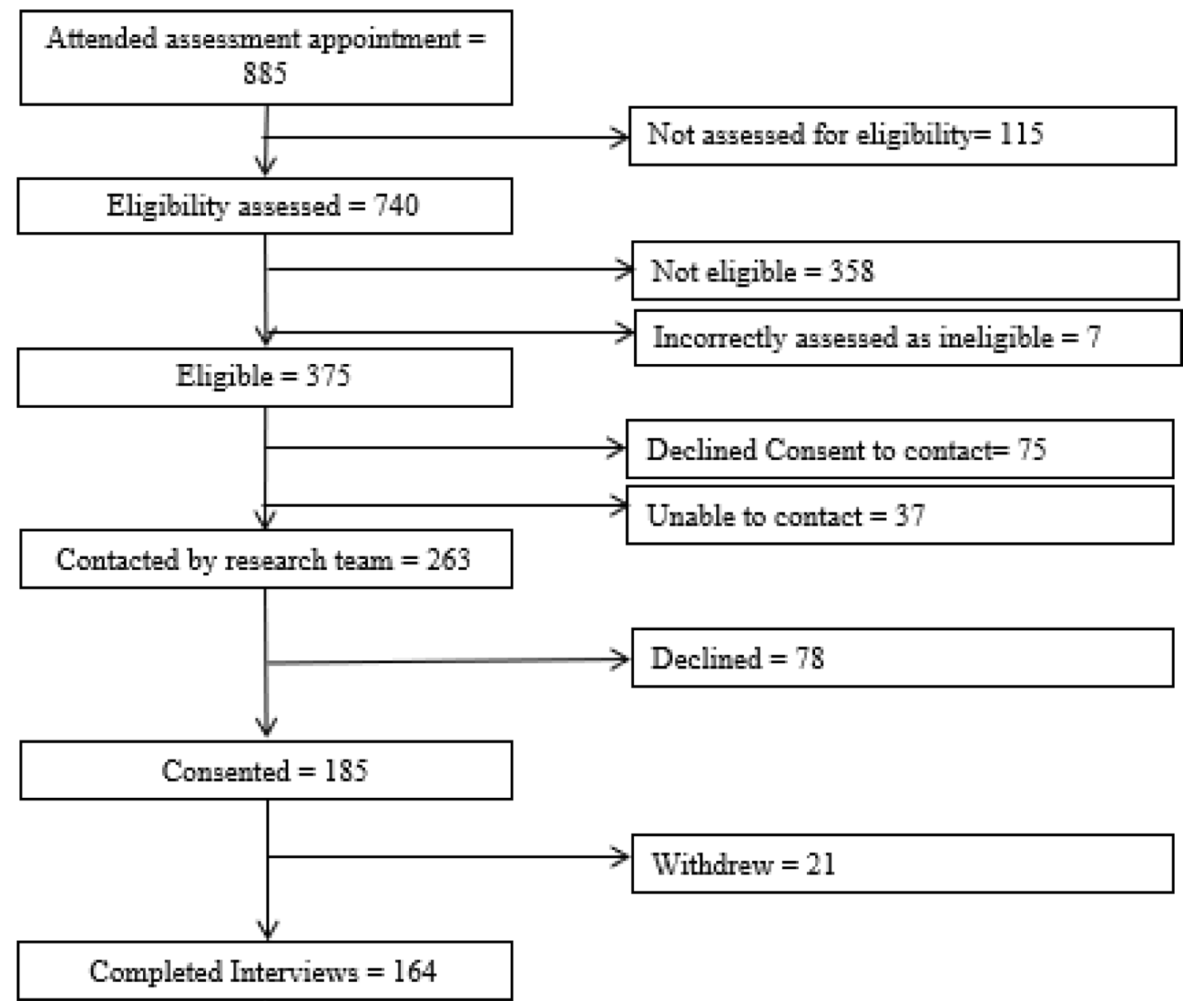

Fig. 1 Consort diagram showing number of participants at each stage of recruitment

\section{Data analysis}

The data were analysed using IBM SPSS Statistics 23 and MedCalc. Participants were classified as having DSM-5 defined MDD, panic, agoraphobia, separation anxiety, social anxiety, phobic, generalised anxiety, obsessive compulsive or posttraumatic stress disorder based on the KSADS interview. Descriptive statistics were analysed to determine the prevalence of anxiety disorders and MDD.

The diagnostic interview, the KSADS, was the gold standard against which the questionnaire scores were compared. Receiver-operating characteristic (ROC) curves were constructed using the DeLong method and the diagnostic accuracy of the RCADS-D, RCADS-any anxiety disorder, SCAS, HADS-D and HADS-A was quantified using the area under the ROC curve (AUC). An AUC of $\geq 0.7$ was assumed to indicate at least moderate accuracy in identifying those who have depression/anxiety. For clinical purposes, sensitivity was considered more desirable than specificity; therefore, we sought the optimal threshold which had a sensitivity of $\geq 0.8$ and specificity of $\geq 0.7$.

\section{Results}

Of the 375 patients who attended an initial clinical assessment appointment and were assessed as meeting the eligibility criteria, $263(70.1 \%)$ agreed to further contact from the research team and $185(70.3 \%)$ of these consented to participate in the study, with 21 subsequently withdrawing (see Fig. 1). Those who were recruited were similar to those who were not recruited (i.e. eligible, but not offered the opportunity to participate by clinicians or declined consent to contact, see Supplementary Information Table S1). Of the 164 patients $(43.7 \%$ of those eligible) interviewed, most were females $(70.1 \%)$. The mean age was 14.99 years, mainly White British participants (see Table 1). Only 13 (7.9\%) participants were attending school full time, with 67 (40.8\%) participants 
Table 1 Characteristics of the sample

\begin{tabular}{|c|c|c|c|}
\hline \multicolumn{4}{|l|}{ Gender } \\
\hline Male & & & 49 (29.9\%) \\
\hline Female & & & $115(70.1 \%)$ \\
\hline \multicolumn{4}{|l|}{ Ethnic origin } \\
\hline White British & & & $146(89.0 \%)$ \\
\hline Unspecified & & & $10(6.1 \%)$ \\
\hline Other White & & & $6(3.7 \%)$ \\
\hline Other British & & & $1(0.6 \%)$ \\
\hline \multirow[t]{2}{*}{ Pakistani } & & & $1(0.6 \%)$ \\
\hline & Range & Mean (SD) & Cronbach's $\alpha$ \\
\hline Age (years) & $12-18$ & $14.99(1.50)$ & \\
\hline SCAS total & $3-99$ & 34.44 (17.97) & 0.93 \\
\hline HADS-D total & $0-18$ & 7.85 (3.76) & 0.76 \\
\hline RCADS-A & $5-78$ & $35.28(20.73)$ & 0.96 \\
\hline RCADS-D & $2-27$ & $15.02(5.38)$ & 0.84 \\
\hline CFQ & $11-33$ & $25.25(4.47)$ & 0.83 \\
\hline SF36PFS & $0-100$ & $51.66(24.04)$ & 0.90 \\
\hline
\end{tabular}

$C F Q$ Chalder Fatigue Questionnaire, HADS-A Hospital Anxiety and Depression Scale-Anxiety, HADS-D Hospital Anxiety and Depression Scale-Depression, RCADS-A Revised Children's Anxiety and Depression Scale-Any Anxiety, RCADS-D Revised Children's Anxiety and Depression Scale-Depression, SCAS Spence Children's Anxiety Scale, SF36PFS Short Form 36 Physical Functioning Subscale

attending less than $40 \%$ of the time and the participant mean score on the SF36PFS as a measure of disability was 51.66, which is comparable to other cohort studies in the same setting [2, 27, 35] (see Supplementary Materials Table S2). In almost all cases, a parent was interviewed as well as the adolescent themselves $(N=156,95 \%)$. The majority $(N=140)$ were mothers. In 9 instances, fathers were interviewed and both parents in seven instances.

Table 2 Number of participants meeting DSM-5 diagnostic criteria on the KSADS

\begin{tabular}{ll}
\hline Disorder & $\begin{array}{l}\text { Participants who } \\
\text { received diagnosis- } \\
N(\%)\end{array}$ \\
\hline Major depressive disorder & $33(20.1)$ \\
Any anxiety disorder & $45(27.4)$ \\
Panic & $6(3.7)$ \\
Agoraphobia & $4(2.4)$ \\
Separation anxiety & $1(0.6)$ \\
Social anxiety & $19(11.6)$ \\
Phobia & $14(8.5)$ \\
Generalised anxiety disorder (GAD) & $17(10.4)$ \\
Obsessive compulsive disorder (OCD) & a \\
Eating disorder & $3(1.8)$ \\
Post-traumatic stress disorder (PTSD) & 0 \\
\hline
\end{tabular}

${ }^{a}$ OCD was included as an anxiety disorder, but PTSD was not, as this is consistent with the PROMs used
Out of the 164 participants recruited, 58 (35.4\%) met the criteria for at least one mental health diagnosis of whom $13(7.9 \%)$ had major depressive disorder (MDD) only, 25 $(15.2 \%)$ had an anxiety disorder only. Approximately a third $(20,34.5 \%)$ had both anxiety and depression which means that 33 participants $(20 \%, 95 \%$ CI $13.1-27.1)$ met the criteria for MDD and 45 participants $(27.4 \%, 95 \% \mathrm{CI}$ 20.4-34.4) met the criteria for at least one anxiety disorder (see Table 2).

Consistent with the predominance of females in the sample, more females than males were diagnosed with depression $(N=23,69.7 \%$ female) and anxiety $(N=34,75.6 \%)$. The mean age of those meeting diagnostic criteria on the KSADS was slightly higher than the overall sample mean, but not significantly so (depression: mean difference $=0.22$, 95\% CI $-0.34-0.78, p=0.435$; Anxiety: mean difference $=0.41,95 \% \mathrm{CI}-0.08-0.90, p=0.101)$.

The most prevalent anxiety disorder types were social anxiety disorder $(N=19,11.6 \%)$ and generalised anxiety disorder $(N=17,10.4 \%)$. Fourteen $(8.5 \%)$ had a phobic disorder with 4 participants meeting the criteria for an animal phobia, 4 natural environment phobias (e.g. thunderstorms, heights), 1 blood/injection/injury phobia and 5 situational type phobias (e.g. planes, elevators). Only one participant met the full diagnostic criteria for separation anxiety disorder, although a further $16(9.8 \%)$ presented with subthreshold symptoms of separation anxiety. Thirty participants met the criteria for only one anxiety disorder diagnosis, with 11 
meeting criteria for two anxiety disorders and 4 meeting the criteria for three anxiety disorders.

Of the 33 diagnosed with co-morbid depression, the vast majority $(N=30,90.9 \%)$ had significant fatigue which they perceived to be linked to and exacerbated by their mood, over and above fatigue from their CFS/ME. Furthermore, cognitive difficulties were fairly pervasive $(N=29,87.9 \%)$. Most had depressed mood $(N=23,69.7 \%)$ and/or psychomotor retardation or agitation $(N=23,69.7 \%)$. Many also had difficulties sleeping $(N=21,63.6 \%)$ and/or irritability $(N=21,63.6 \%)$. Relatively few $(N=6,18.2 \%)$ had suicidal thinking or feelings of worthlessness $(N=13,39.4 \%)$. Anhedonia was described in just over $50 \%$ of the sample (see Table 3).

All PROMs (i.e. the RCADS, HADS and SCAS) scored $>0.7$ for area under the curve, AUC, indicating at least moderate accuracy (see Table 4 and Figs. 2 and 3). The RCADS-A performed the best and both the brief and full version were similar with little difference between the raw scores and the age- and gender-adjusted T scores. For all versions of the RCADS-A, we identified threshold scores reaching the required $\geq 0.8$ sensitivity and $\geq 0.7$ specificity thresholds. We could not identify scores on the HADS-A and SCAS which reached these thresholds (see Table 4). None of the depression measures were sufficiently accurate to reach the $0.8 / 0.7$ requirement (see Table 4 ).

\section{Discussion}

This is the first large clinical cohort study to accurately measure both anxiety and depression using diagnostic interviews applying DSM-5 criteria in adolescents with CFS/ME. We found that 1 in 3 met the diagnostic criteria

Table 3 Frequency of threshold symptoms of depression on the KSADS in those diagnosed with Major depressive disorder (MDD)data shown as $N(\%)$

\begin{tabular}{lr}
\hline DSM symptom & Yes \\
\hline Depressed mood & $23(69.7)$ \\
Irritable mood & $21(63.6)$ \\
Anhedonia & $18(54.5)$ \\
Appetite/weight change & $17(51.5)$ \\
Insomnia/hypersomnia & $21(63.6)$ \\
Psychomotor agitation/retardation & $23(69.7)$ \\
Fatigue $^{\text {a }}$ & $30(90.9)$ \\
Feelings of worthlessness/excessive or inappropriate guilt & $13(39.4)$ \\
Reduced concentration/slowed thinking/indecisiveness $^{\text {Recurrent thoughts of death/suicidal ideation/suicide }}$ & $29(87.9)$ \\
$\quad$ attempt & $6(18.2)$ \\
\hline
\end{tabular}

${ }^{a}$ Fatigue was scored as threshold only if it was perceived to be linked to mood by (1) becoming more prominent at the onset of the low mood episode and/or (2) tending to be worse when mood was worse for a common mental health disorder. The majority of those who met the criteria for a mental health problem had both anxiety and depression; $20 \%$ of adolescents attending a specialist CFS/ME service meet the criteria for Major Depressive Disorder (MDD) and 27\% the criteria for at least one anxiety disorder. Some met the criteria for up to three co-occurring anxiety disorders. The high co-morbidity in this group suggests that if one is diagnosed, the other needs to be screened for. Unlike in other conditions, the PROMs were not sufficiently accurate, apart from the RCADS-A (self-report and parent versions) and even using the optimum cutoffs that we identified will likely result in false positives and false negatives.

Consistent with the epidemiology of CFS/ME [36], we recruited more females than males. Despite the recruitment difficulties encountered [37], the participants recruited to this study were comparable to those recruited in other cohort studies and randomised controlled trials in the same service setting (see Supplementary Materials Table S3).

This study is consistent with the previous work, which shows that depression and anxiety are higher in adolescents with CFS/ME [5, 8, 9, 38] than in healthy populations [39, 40]. The high rates of depression and anxiety seen in adolescents with CFS/ME could be due to a variety of factors including social loss [41-43], the inability to take part in activities [41, 42] or other underlying causal factors including shared genetic vulnerability [44] and previous trauma $[45,46]$. Alternatively, a tendency to avoid anxiety-provoking situations, such as phobic stimuli or physical activity following a viral infection, could independently contribute to both anxiety and CFS/ME, for instance [47, 48].

We found high rates of anxiety disorders. This is particularly striking given that the KSADS applies stricter criteria than the Anxiety Diagnostic Interview Schedule (ADIS), which is most commonly used in anxiety studies [49]. We did not show the high rates of separation anxiety found in previous work [5]. This may be because previous studies recruited younger participants, more likely to be experiencing separation anxiety disorder [50]. Alternatively, it may be because of the reliance of previous studies on questionnaires, which meant that they were unable to distinguish between those with raised separation fears (which were common in our sample) and those meeting the full diagnostic criteria for separation anxiety disorder. The level of specific phobia was comparable to general population samples of adolescents [51, 52]. The high levels of Generalised Anxiety Disorder are a new finding. This may be because of a general tendency to avoid anxiety-provoking situations $[47,48]$ or shared vulnerability [53].

In those adolescents who were depressed, the pattern of symptoms was different to that commonly found in samples recruited via Child and Adolescent Mental Health Services $[54,55]$. Rates of suicidal ideation and feelings of 
Table 4 ROC analysis for PROMs

\begin{tabular}{|c|c|c|c|c|c|c|c|c|c|}
\hline & Measure & AUC & SE of AUC & $95 \% \mathrm{CI}$ for $\mathrm{AUC}$ & $Z$ statistic for AUC & \multicolumn{2}{|c|}{$\begin{array}{l}\text { Optimum } \\
\text { threshold for } \\
\text { diagnosis }\end{array}$} & Sensitivity & Specificity \\
\hline \multicolumn{10}{|c|}{ Adolescent self-reported measures } \\
\hline \multirow[t]{3}{*}{$\begin{array}{l}\text { Depression } \\
\text { (MDD) }\end{array}$} & $\begin{array}{l}\text { RCADS-D raw } \\
\text { score }\end{array}$ & 0.789 & 0.0464 & $0.690-0.869$ & 6.238 & $>15$ & $>14$ & $\begin{array}{l}92.00 \\
72.00\end{array}$ & $\begin{array}{l}59.38 \\
68.75\end{array}$ \\
\hline & RCADS-D $t$ score & 0.787 & 0.0485 & $0.685-0.869$ & 5.929 & $>69$ & $>68$ & $\begin{array}{l}80.00 \\
72.00\end{array}$ & $\begin{array}{l}63.33 \\
66.67\end{array}$ \\
\hline & HADS-D & 0.714 & 0.0425 & $0.636-0.783$ & 5.032 & $>8$ & $>7$ & $\begin{array}{l}80.65 \\
67.74\end{array}$ & $\begin{array}{l}55.20 \\
61.60\end{array}$ \\
\hline \multirow{6}{*}{$\begin{array}{l}\text { Anxiety (any } \\
\text { anxiety disorder } \\
\text { diagnosis) }\end{array}$} & $\begin{array}{l}\text { RCADS-A ( } 37 \\
\text { item) raw score }\end{array}$ & 0.879 & 0.0357 & $0.792-0.938$ & 10.602 & $>38$ & $>37$ & $\begin{array}{l}86.67 \\
80.00\end{array}$ & $\begin{array}{l}72.88 \\
76.27\end{array}$ \\
\hline & $\begin{array}{c}\text { RCADS-A ( } 37 \\
\text { item) } t \text { score }\end{array}$ & 0.889 & 0.0347 & $0.802-0.947$ & 11.221 & $>56$ & $>55$ & $\begin{array}{l}86.67 \\
86.67\end{array}$ & $\begin{array}{l}80 \\
81.82\end{array}$ \\
\hline & $\begin{array}{l}\text { RCADS-A (15 } \\
\text { item) raw score }\end{array}$ & 0.890 & 0.0337 & $0.806-0.946$ & 11.582 & $\begin{array}{l}>11 \\
>12\end{array}$ & $>10$ & $\begin{array}{l}93.33 \\
90.00 \\
80\end{array}$ & $\begin{array}{l}\mathbf{7 2 . 8 8} \\
\mathbf{7 4 . 5 8} \\
\mathbf{7 7 . 9 7}\end{array}$ \\
\hline & $\begin{array}{l}\text { RCADS-A (15 } \\
\text { item) } t \text { score }\end{array}$ & 0.889 & 0.0347 & $0.802-0.947$ & 11.221 & & $>56$ & 86.67 & 81.82 \\
\hline & HADS-A & 0.774 & 0.0403 & $0.700-0.837$ & 6.795 & $>10$ & $>9$ & $\begin{array}{l}83.33 \\
71.43\end{array}$ & $\begin{array}{l}60.18 \\
68.14\end{array}$ \\
\hline & SCAS & 0.744 & 0.0449 & $0.665-0.814$ & 5.438 & $>39$ & $>37$ & $\begin{array}{l}76.32 \\
71.05\end{array}$ & $\begin{array}{l}70.48 \\
76.19\end{array}$ \\
\hline \multicolumn{10}{|c|}{ Parent informant-reported measures } \\
\hline \multirow[t]{2}{*}{$\begin{array}{l}\text { Depression } \\
\text { (MDD) }\end{array}$} & $\begin{array}{l}\text { RCADSP-D raw } \\
\text { score }\end{array}$ & 0.780 & 0.0517 & $0.688-0.869$ & 5.582 & & $>15$ & 69.6 & 79.7 \\
\hline & RCADSP D $t$ score & 0.787 & 0.0485 & $0.685-0.869$ & 5.929 & & $>68$ & 80 & 63.33 \\
\hline \multirow{4}{*}{$\begin{array}{l}\text { Anxiety (any } \\
\text { anxiety disorder } \\
\text { diagnosis) }\end{array}$} & $\begin{array}{l}\text { RCADSP-A ( } 37 \\
\text { item) }\end{array}$ & 0.858 & 0.0417 & $0.765-0.924$ & 8.565 & & $>31$ & 83.33 & 76.36 \\
\hline & $\begin{array}{l}\text { RCADSP-A ( } 37 \\
\text { item) } t \text { score }\end{array}$ & 0.858 & 0.0438 & $0.762-0.925$ & 8.162 & $>64$ & $>62$ & $\begin{array}{l}83.33 \\
80.00\end{array}$ & $\begin{array}{l}78.43 \\
80.39\end{array}$ \\
\hline & $\begin{array}{l}\text { RCADSP-A (15 } \\
\text { item) }\end{array}$ & 0.780 & 0.0517 & $0.765-0.922$ & 8.449 & & $>9$ & 80.00 & 75.44 \\
\hline & $\begin{array}{l}\text { RCADSP-A ( } 15 \\
\text { item) } t \text { score }\end{array}$ & 0.861 & 0.0421 & $0.767-0.928$ & 8.572 & & $>58$ & 80.00 & 75.00 \\
\hline
\end{tabular}

Bold indicates that the minimum required 0.8 sensitivity/0.7 specificity criterion is met by this threshold score

worthlessness were particularly low, which may be due to referral criteria for different specialist services, with those who report suicidal ideation more likely to be referred to mental health services. Rates of somatic symptoms including fatigue and cognitive difficulties were extensive in our sample, which are also common in adolescents with CFS/ $\mathrm{ME}$ [35] and may be compounded in those who have comorbid depression. It may also be that there are different subtypes of depression, including an inflammation-linked somatic subtype, which is more frequent in CFS/ME [56]. Our findings suggest that depression in adolescents CFS/ ME may be characterised less by negative self-perceptions and self-injurious behaviours and more by anhedonia and somatic symptoms.

Whilst this is the first study to accurately define the prevalence of both anxiety and depression in CFS/ME, the high rate of comorbidity between the two is perhaps not surprising given the co-occurrence in healthy adolescents [57]. It does; however, mean that clinicians and clinical services ought to screen for both mood and anxiety disorders when planning treatment.

As the KSADS diagnostic interview is too resource intensive for use in most routine clinical care settings, a screening measure that is sufficiently accurate and appropriate for the population is urgently needed. Apart from the RCADS anxiety, the PROMs we examined did not meet our pre-specified criteria for accuracy. It is encouraging that both the self- and parent-report versions of the RCADS anxiety subscale (37 items) and the brief versions of this ( 15 items) did meet these criteria. In CFS/ME, reducing burden on patients is of utmost importance and using the brief version (although this is at the cost of information about specific anxiety disorder 
Fig. 2 Receiver operating curves for depression measures

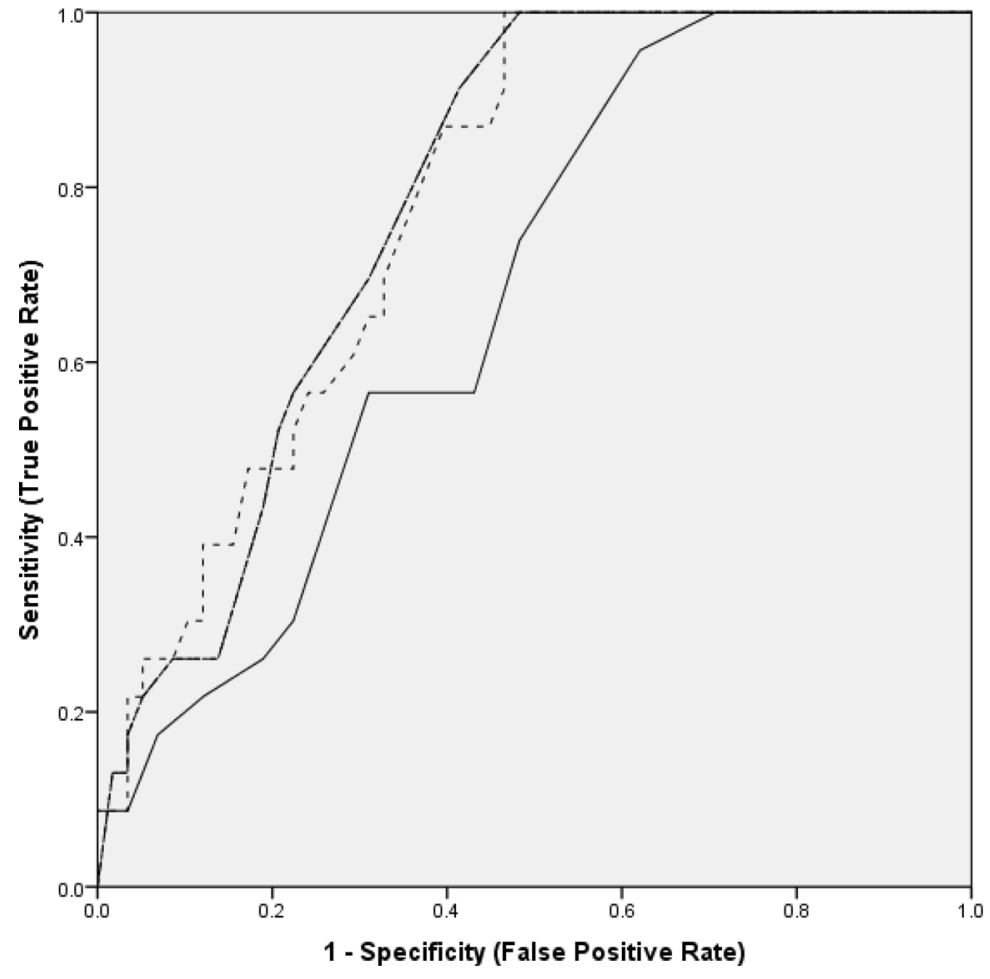

types) and using parent informants where adolescents are too unwell to complete the questionnaire themselves could be useful. The RCADS-depression subscale did not meet the criteria for accuracy. Furthermore, the HADS did not meet the required accuracy criteria for either depression or anxiety; we would therefore recommend that services use other PROMs such as the RCADS for anxiety. The HADS was developed for adults and then validated for use in adolescents, whilst the RCADS was specifically developed for children and adolescents and may therefore be more
Fig. 3 Receiver operating curves for anxiety measures

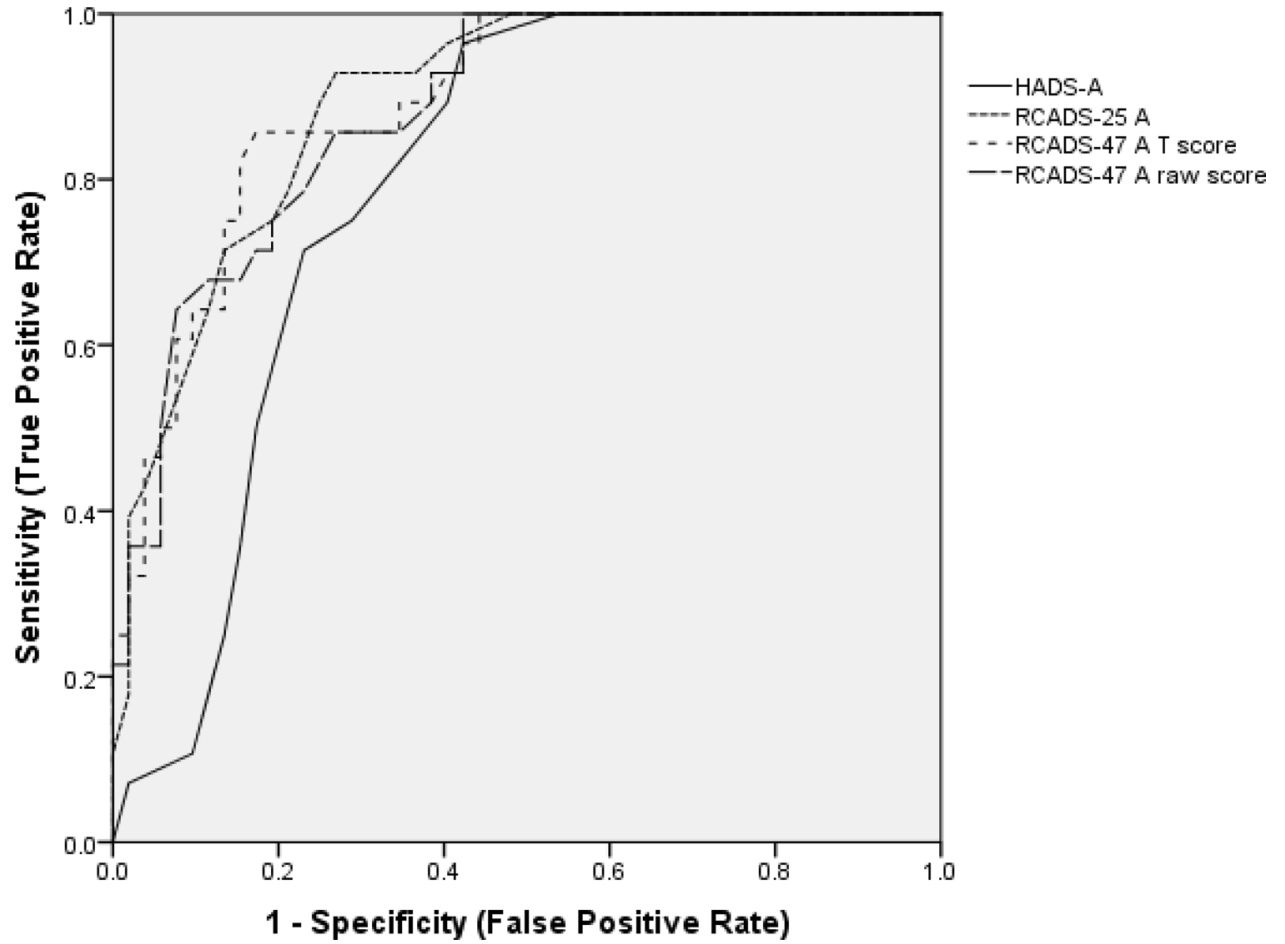


developmentally appropriate. A more accurate self-report measure of depression symptoms among adolescents with CFS/ME is needed. The Mood and Feelings Questionnaire [58] which is the gold standard questionnaire for screening for depression in adolescents [59] and may overlap less with the core symptoms of CFS/ME could be worth investigating.

\section{Strengths and limitations}

This is a considerably larger study than has previously been undertaken in adolescents with CFS/ME. However, we did not include under $12 \mathrm{~s}$ and cannot make any conclusions about anxiety and depression in children. We used diagnostic interviews, assessed the latest DSM-5 criteria and aimed to recruit all eligible patients seen within the largest specialist paediatric CFS/ME clinic in the UK. Whilst our sample is large, many patients declined to participate so our sample may not be fully representative of the population seen in this clinic or wider services. Furthermore, our findings may not apply to settings other than specialist services. Finally, whilst the KSADS is the best diagnostic instrument for diagnosing depression, it may not always be $100 \%$. Accuracy depends on the diagnostic judgements by trained raters. This needs to be acknowledged, but we minimised this possibility through training and individual case review.

\section{Conclusion}

A substantial minority of adolescents with CFS/ME meet diagnostic criteria for a co-morbid major depressive disorder or an anxiety disorder (generalised anxiety, social anxiety and specific phobia are most common) or both. Identifying patients who are experiencing mental health problems is key to treatment for both CFS/ME and psychological distress and to enabling recovery and maximising functioning. Clinicians need to be aware that symptoms typically associated with depression (such as suicidal thinking) and anxiety are not necessarily present in adolescents with CFS/ME. Many patients have both anxiety and depression; therefore, clinicians should screen for one if they find the other. A full clinical assessment should be used alongside the RCADS questionnaire. Clinicians in paediatric settings may benefit from additional training in identifying mental health problems in adolescents with CFS/ME specifically. A combination of qualitative and longitudinal epidemiological research would shed further light on the factors which contribute to anxiety amongst this population.

Acknowledgements The authors would like to thank all the young people and families who took part in this study and healthcare professionals in at the recruitment site who supported the study. The authors are also grateful to Soraya Safazadeh, Nikos Vrontaras, Matilda
Wyn-Griffiths and Jiedi Lei for their help with data collection. The authors would like to extend their thanks to Anna Brooke for her support with navigating ethics processes and to Richard Morris for his statistical advice.

Funding Prof Crawley was funded during data collection by the National Institute for Health Research (Senior Research Fellowship, SRF-2013-06-013). Dr Loades is funded by an NIHR Doctoral Research Fellowship (DRF-2016-09-021). This report is independent research. The views expressed in this publication are those of the authors(s) and not necessarily those of the NHS, NIHR or the Department of Health and Social Care. All authors have indicated they have no financial relationships relevant to this article to disclose.

\section{Compliance with ethical standards}

Conflict of interest EC acts as a medical advisor for the Sussex and Kent ME society. The other authors declare that there is no conflict of interest.

Open Access This article is licensed under a Creative Commons Attribution 4.0 International License, which permits use, sharing, adaptation, distribution and reproduction in any medium or format, as long as you give appropriate credit to the original author(s) and the source, provide a link to the Creative Commons licence, and indicate if changes were made. The images or other third party material in this article are included in the article's Creative Commons licence, unless indicated otherwise in a credit line to the material. If material is not included in the article's Creative Commons licence and your intended use is not permitted by statutory regulation or exceeds the permitted use, you will need to obtain permission directly from the copyright holder. To view a copy of this licence, visit http://creativecommons.org/licenses/by/4.0/.

\section{References}

1. Brigden A, Loades M, Abbott A, Bond-Kendall J, Crawley E (2017) Practical management of chronic fatigue syndrome or myalgic encephalomyelitis in childhood. Arch Dis Child 102:981-986

2. Bould H, Collin SM, Lewis G, Rimes KA, Crawley E (2013) Depression in paediatric chronic fatigue syndrome. Arch Dis Child 98(6):425-428

3. Bould H, Lewis G, Emond A, Crawley E (2011) Depression and anxiety in children with CFS/ME: cause or effect? Arch Dis Child 96(3):211-214

4. Walford GA, Nelson WM, McCluskey DR (1993) Fatigue, depression, and social adjustment in chronic fatigue syndrome. Arch Dis Child 68(3):384-388

5. Crawley E, Hunt L, Stallard P (2009) Anxiety in children with CFS/ME. Eur Child Adolesc Psychiatry 18(11):683-689

6. Parslow RM, Patel A, Beasant L, Haywood K, Johnson D, Crawley E (2015) What matters to children with CFS/ME? A conceptual model as the first stage in developing a PROM. Arch Dis Child 100:1141-1147

7. Haywood KL, Collin SM, Crawley E (2014) Assessing severity of illness and outcomes of treatment in children with chronic fatigue syndrome/myalgic encephalomyelitis (CFS/ME): a systematic review of patient-reported outcome measures (PROMs). Child Care Health Dev 40(6):806-824

8. Garralda ME, Rangel L (2005) Chronic fatigue syndrome of childhood. Comparative study with emotional disorders. Eur Child Adolesc Psychiatry 14(8):424-430 
9. Loades ME, Rimes KA, Ali S, Lievesley K, Chalder T (2017) The presence of co-morbid mental health problems in a cohort of adolescents with chronic fatigue syndrome. Clin Child Psychol Psychiatry 23:398-408

10. Brigden A, Beasant L, Hollingworth W et al (2016) Managed activity graded exercise iN teenagers and pre-adolescents (MAGENTA) feasibility randomised controlled trial: study protocol. BMJ Open 6(7):e011255

11. Kaufman J, Birmaher B, Axelson D, Perepletchikova F, Brent D, Ryan N (2013) Schedule for affective disorders and schizophrenia for school-age children-present and lifetime version (K-SADS-PL 2013, DSM-5). Western Psychiatric Institute and Yale University, Pittsburgh

12. Simmons M, Wilkinson P, Dubicka B (2015) Measurement issues: depression measures in children and adolescents. Child Adolesc Mental Health 20(4):230-241

13. NICE (2005) Depression in children and young people: Identification and management in primary, community and secondary care. In: Excellence NIoHaC (eds) NICE clinical guideline, 282005. https://www.nice.org.uk/guidance/cg28

14. APA (2013) Diagnostic and statistical manual of mental disorders: DSM-5. American Psychiatric Association, Washington

15. Chorpita BF, Yim L, Moffitt C, Umemoto LA, Francis SE (2000) Assessment of symptoms of DSM-IV anxiety and depression in children: a revised child anxiety and depression scale. Behav Res Ther 38(8):835-855

16. Chorpita BF, Moffitt CE, Gray J (2005) Psychometric properties of the revised child anxiety and depression scale in a clinical sample. Behav Res Ther 43(3):309-322

17. Esbjorn BH, Somhovd MJ, Turnstedt C, Reinholdt-Dunne ML (2012) Assessing the revised child anxiety and depression scale (RCADS) in a national sample of Danish youth aged 8-16 years. PLoS ONE 7(5):e37339

18. Gormez V, Kılınçaslan A, Orengul AC et al (2017) Psychometric properties of the Turkish version of the revised child anxiety and depression scale — child version in a clinical sample. Psychiatry Clin Psychopharmacol 27(1):84-92

19. Zigmond A, Snaith R (1983) The hospital anxiety and depression scale. Acta Psychiatr Scand 67(6):361-370

20. White D, Leach C, Sims R, Atkinson M, Cottrell D (1999) Validation of the hospital anxiety and depression scale for use with adolescents. Br J Psychiatry 175:452-454

21. Spence SH (1998) A measure of anxiety symptoms among children. Behav Res Ther 36(5):545-566

22. Spence SH, Barrett PM, Turner CM (2003) Psychometric properties of the Spence Children's Anxiety Scale with young adolescents. J Anxiety Disord 17(6):605-625

23. APA (2000) Diagnostic and statistical manual of mental disorders: DSM-IV-TR. American Psychiatric Association, Washington

24. Orgilés M, Fernández-Martínez I, Guillén-Riquelme A, Espada JP, Essau CA (2016) A systematic review of the factor structure and reliability of the Spence Children's Anxiety Scale. J Affect Disord 190:333-340

25. Chalder T, Berelowitz G, Pawlikowska T et al (1993) Development of a fatigue scale. J Psychosom Res 37(2):147-153

26. Cella M, Chalder T (2010) Measuring fatigue in clinical and community settings. J Psychosom Res 69(1):17-22

27. Crawley EM, Gaunt DM, Garfield K et al (2018) Clinical and costeffectiveness of the Lightning Process in addition to specialist medical care for paediatric chronic fatigue syndrome: randomised controlled trial. Arch Dis Child 103:155-164

28. Chalder T, Deary V, Husain K, Walwyn R (2010) Family-focused cognitive behaviour therapy versus psycho-education for chronic fatigue syndrome in 11- to 18-year-olds: a randomized controlled treatment trial. Psychol Med 40(08):1269-1279
29. Ware JE, Sherbourne CD (1992) The MOS 36-item short-form health survey (SF-36): I. Conceptual framework and item selection. Med Care 30:473-483

30. Loades M, Vitoratou S, Rimes K, Chalder T (2020) Assessing functioning in adolescents with chronic fatigue syndrome: psychometric properties and factor structure of the School and Social Adjustment Scale and the Physical Functioning Subscale of the SF36. Behav Cogn Psychother 48:1-11

31. Harris P, Taylor R, Thielke R, Payne J, Gonzalez N, Conde J (2012) Citing REDCap. https://www.project-redcap.org/cite.php. Accessed 10 Oct 2019

32. Green JG, Avenevoli S, Finkelman M et al (2010) Attention deficit hyperactivity disorder: concordance of the adolescent version of the composite international diagnostic interview version 3.0 (CIDI) with the K-SADS in the US National Comorbidity Survey Replication Adolescent (NCS-A) supplement. Int J Methods Psychiatr Res. 19(1):34-49

33. Nrugham L, Larsson B, Sund AM (2008) Specific depressive symptoms and disorders as associates and predictors of suicidal acts across adolescence. J Affect Disord 111(1):83-93

34. Jordan C, Ohlsen R, Hayee B, Chalder T (2017) A qualitative study exploring the experience of people with IBD and elevated symptoms of anxiety and low mood and the type of psychological help they would like. Psychol Health 33:1-18

35. Collin S, Nuevo R, van de Putte EM, Nijhof SL, Crawley E (2015) Chronic fatigue syndrome (CFS) or myalgic encephalomyelitis (ME) is different in children compared to in adults: a study of UK and Dutch clinical cohorts. BMJ open 5(10):e008830

36. Crawley E (2014) The epidemiology of chronic fatigue syndrome/ myalgic encephalitis in children. Arch Dis Child 99(2):171-174

37. Loades ME, Smith L, Higson-Sweeney N et al (2019) Obstacles to recruitment in paediatric studies focusing on mental health in a physical health context: the experiences of clinical gatekeepers in an observational cohort study. BMC Med Res Methodol 19(1):89. https://doi.org/10.1186/s12874-019-0730-z

38. Garralda ME, Rangel L, Levin M, Roberts H, Ukoumunne O (1999) Psychiatric adjustment in adolescents with a history of chronic fatigue syndrome. J Am Acad Child Adolesc Psychiatry 38(12):1515-1521

39. Polanczyk GV, Salum GA, Sugaya LS, Caye A, Rohde LA (2015) Annual research review: a meta-analysis of the worldwide prevalence of mental disorders in children and adolescents. J Child Psychol Psychiatry 56(3):345-365

40. Avenevoli S, Swendsen J, He JP, Burstein M, Merikangas KR (2015) Major depression in the national comorbidity survey-adolescent supplement: prevalence, correlates, and treatment. J Am Acad Child Adolesc Psychiatry 54(1):37 e32-44 e32

41. Taylor AK, Loades M, Brigden AL, Collin SM, Crawley E (2017) 'It's personal to me': a qualitative study of depression in young people with CFS/ME. Clin Child Psychol Psychiatry 22(2):326-340

42. Parslow RM, Harris S, Broughton J et al (2017) Children's experiences of chronic fatigue syndrome/myalgic encephalomyelitis (CFS/ME): a systematic review and meta-ethnography of qualitative studies. BMJ Open 7(1):e012633

43. Fisher H, Crawley E (2013) Why do young people with CFS/ME feel anxious? A qualitative study. Clin Child Psychol Psychiatry 18(4):556-573

44. Hur Y-M, Burri A, Spector TD (2012) The genetic and environmental structure of the covariation among the symptoms of insomnia, fatigue, and depression in adult females. Twin Res Hum Genet 15(6):720-726

45. Heim C, Nater UM, Maloney E, Boneva R, Jones JF, Reeves WC (2009) Childhood trauma and risk for chronic fatigue syndrome: 
association with neuroendocrine dysfunction. Arch Gen Psychiatry 66(1):72-80

46. Pass L, Mastroyannopoulou K, Coker S, Murray L, Dodd H (2017) Verbal information transfer in real-life: when mothers worry about their child starting school. J Child Fam Stud 26(8):2324-2334

47. Browne T, Chalder T (2006) Chronic fatigue syndrome. Psychiatry $5(2): 48-51$

48. Rachman S, Costello C (1961) The aetiology and treatment of children's phobias: a review. Am J Psychiatry 118(2):97-105

49. Spence SH (2018) Assessing anxiety disorders in children and adolescents. Child Adolesc Mental Health 23(3):266-282

50. Waite P, Creswell C (2014) Children and adolescents referred for treatment of anxiety disorders: differences in clinical characteristics. J Affect Disord 167:326-332

51. Burstein M, Georgiades K, He J-P et al (2012) Specific phobia among US adolescents: phenomenology and typology. Depress Anxiety 29(12):1072-1082

52. Benjet C, Borges G, Stein DJ, Méndez E, Medina-Mora ME (2012) Epidemiology of fears and specific phobia in adolescence: results from the mexican adolescent mental health survey. J Clin Psychiatry 73(2):152-158

53. Vassend O, Røysamb E, Nielsen CS, Czajkowski NO (2018) Fatigue symptoms in relation to neuroticism, anxiety-depression, and musculoskeletal pain. A longitudinal twin study. PLoS ONE 13(6):e0198594
54. Orchard F, Pass L, Marshall T, Reynolds S (2017) Clinical characteristics of adolescents referred for treatment of depressive disorders. Child Adolesc Ment Health 22:61-68. https://doi. org/10.1111/camh.12178

55. Goodyer IM, Reynolds S, Barrett B et al (2017) Cognitive-behavioural therapy and short-term psychoanalytic psychotherapy versus brief psychosocial intervention in adolescents with unipolar major depression (IMPACT): a multicentre, pragmatic, observerblind, randomised controlled trial. Health Technol Assess (Winchester, England) 21(12):1

56. Hickie IB, Carpenter JS, Scott EM (2018) Adolescent-onset depressive disorders and inflammation. Inflammation and immunity in depression. Elsevier, Hoboken, pp 427-443

57. Ferdinand RF, de Nijs PF, van Lier P, Verhulst FC (2005) Latent class analysis of anxiety and depressive symptoms in referred adolescents. J Affect Disord 88(3):299-306

58. Costello EJ, Angold A (1988) Scales to assess child and adolescent depression: checklists, screens, and nets. J Am Acad Child Adolesc Psychiatry 27(6):726-737

59. Thabrew H, Stasiak K, Bavin L-M, Frampton C, Merry S (2018) Validation of the Mood and Feelings Questionnaire (MFQ) and Short Mood and Feelings Questionnaire (SMFQ) in New Zealand help-seeking adolescents. Int J Methods Psychiatr Res 27(3):e1610 